\title{
Geographic Distribution of Oases in Arid Regions
}

\author{
Zafarjon Makhramkulovich Toshboev \\ Senior Lecturer Department of Geography and Fundamentals of Economics Jizzakh State Pedagogical Institute
}

\begin{abstract}
BSTRACT: This article examines the oases that appeared on the inhabited continents of the planet. Historically, in the desert regions formed two main types of irrigated agriculture - small oasis and large oasis. Small oasis farming as a geographical type is developed in the vicinity of small water sources (small streams, streams, springs) in the foothills and in areas where deserts are flooded, groundwater leaks, temporarily adjacent to runoff. The fields of different sizes within the oases made them look like dry sheets, while at the same time showing property and legal inequality.
\end{abstract}

\begin{abstract}
EY WORDS: Oasis landscapes, irrigated agriculture, ditch networks, irrigation structures, ropes, corn, rice, wheat, barley, cotton, various vegetables, fruits, grapes, wheat, alfalfa, melons, vegetables, date palms, water sources, small streams, streams, springs.
\end{abstract}

\section{NTRODUCTION}

In arid regions, there are arid climatic conditions, where the air humidity is insufficient for the growing season of most plants, and agriculture is carried out due to artificial humidification. In arid climates, the annual moisture content does not exceed 30\%, according to N. N. Ivanov. It is dominated by desert and semi-desert landscapes, which are typical for arid countries formed in dry, usually hot and even hot, continental climates. The geosystem of oases, which originated and developed in arid climates and is a zonal type of anthropogenic landscapes, differs from the adjacent desert and semi-desert landscapes in that its natural components are radically altered, constantly man-made. The interaction of geographical components in oasis landscapes also occurs differently than the interaction of components in natural landscapes. Oases differ from other types of anthropogenic landscapes not only by their natural geographical features, but also by the complexity, diversity, structural-dynamic development of their morphological structure.

A.Abdulkasimov, Yu.Abdurahmanova, K.Davronov (2017) The geographical distribution of oasis landscapes in the regions of Central Asia and Uzbekistan with arid climatic conditions is also mainly river and river valleys, basins, the mountain is inextricably linked with the proluvial-alluvial plains, mountain slopes, conical distributions, and springs. All anthropogenic oasis landscapes formed in our country are located in the valleys of the Amudarya, Syrdarya and Zarafshan rivers, in the basins of Fergana, Tashkent, Mirzachul, Zarafshan, Surkhandarya and Kashkadarya, in the deltas of major rivers [1, p.4].

\section{HE MAIN FINDINGS AND RESULTS}

Due to the natural conditions of arid climatic zones, which are formed on the basis of latitudinal zoning in all inhabited continents of the planet, from ancient times people had to farm on the basis of irrigated agriculture. Historically, in the desert regions formed two main types of irrigated agriculture - small oasis and large oasis. Small oasis farming as a geographical type is developed in the vicinity of small water sources (small streams, streams, springs) in the foothills and in areas where deserts are flooded, groundwater leaks, temporarily adjacent to runoff. In the use of such water sources, the water was diverted to the canals or sprinkled on the crop as if moistened by atmospheric precipitation. Small-scale oasis farming was practiced by a small number of people who used simple tools of labor, lived as a community, and met their daily needs. Large oasis farming networks, on the other hand, are formed along the streams in the deltas and valleys of large and medium-sized rivers, and are more complex 
to manage and an economic system was established, a group of people with centralized authority formed to organize the distribution of water through a network of canals. The centralization of affairs led to the consolidation of feudal states in the Amudarya delta (Khorezm), the Zarafshan valley delta (Bukhara), the Murgab river delta (ancient Merv). The fields of different sizes within the oases made them look like dry sheets, while at the same time showing property and legal inequality.

The fields of different sizes within the oases made them look like dry sheets, while at the same time showing property and legal inequality. Water resources were inadequate in proportion to irrigated areas in poor years. Water-supplied and non-water-supplied or conditionally irrigated oases were formed. This has led to crop structure, specialization, and the growth of irrigated areas. In the Atrek river valley it is possible to cultivate fine-fiber cotton, grain crops, which do not require water depending on climatic conditions; In the Karshi desert, irrigated lands are conditionally irrigated; cotton is grown in years when there is a lot of water, and cereals can be grown in years when there is less water. Sesame and melon crops are grown on the Tajan River, as the river dries up in summer: in spring, a strong flood carries a huge mass of water to the remote Karakum sands. The locals, who could not control such a flow of water, limited themselves to growing cereals and melons in the wetlands of the river, and the main occupation of the population was cattle-breeding.

Like other oases in the Central Asian region, local farmers tried to divert water from the Syrdarya to Mirzachul. This is evidenced by the Urinboy-Oguz and Bukhara canals, the traces of which have survived to this day. Indigenous peoples have long dreamed of irrigating and developing the protected lands of the Mirzachul oasis. According to historical sources, in the 16th century the Mirzachul region was called the Jizzakh-Chinoz desert. The results of the research revealed that Abdullah Khan paid great attention to the issues of irrigation and development of vacant lands here. Archaeological excavations have shown that a reservoir was built in the Beklarsay gorge of Nurata district on the instructions of Abdullah. The technical characteristics of this reservoir dam are close to those currently under construction. Its remains have survived to the present day $[6,8]$.

Along with the construction of the Mirzachul irrigation network and the improvement of its technical condition, work has been done to put new lands into agricultural use. As a result, by 1956 the area of irrigated lands in the area of the old irrigated main canal named after Kirov was increased to 206,000 hectares. Thus, for 40 years, 172,000 hectares of irrigated land were developed in Mirzachul. The South Mirzachul canal, which receives water from the Syrdarya, has been launched, and an anthropogenic hydrographic network has been created, equipped with its networks and a number of irrigation and hydraulic structures. In the newly developed lands, several districts and farms of Syrdarya and Jizzakh regions have been established, housing, roads, transport and communication systems have been created. The Central Mirzachul collector is located along the line of Ettisoy, Sardoba, Karoy lowlands, the route of which divides the territory of Mirzachul into two parts. The lands north of the central Mirzachul (formerly irrigated area) are now often regarded as reclamation objects with the help of vertical drainage, as they are covered with thick gravel and fine-grained river sand at a depth of 20-30 m, Lands south of the Central Mirzachul Canal (new irrigated area) are generally considered to be reclaimed by horizontal drainage, as there is no sediment layer in this part of the area, which is important for good permeability in the soil layer. Currently, the irrigation facilities built in the developed part of the Mirzachul oasis consist mainly of four systems - the Kirov main canal system, the South Mirzachul canal system, the Central canal system and the system of machine-irrigated canals [5, 143-145 p].

Taking into account the topography, soil composition, hydrogeological conditions of the landscape of Mirzachul oasis, the system of canals within the concrete-covered farms and farms, as well as the use of a network of trays for distribution and delivery of water to arable lands. In this case, the absorption of water is prevented by a concrete cover with a depth of $2 \mathrm{~m}$ and a width of up to $5 \mathrm{~m}$. Water from the canals is delivered using 6,7 and $8 \mathrm{~m}$ long, 70, 100 and $150 \mathrm{~cm}$ wide trays of reinforced concrete construction, from which polyethylene film is delivered to the trenches through the hoses. If water flows through the longitudinal axes, suffocation processes may increase. In the newly developed part of Mirzachul, between the two cards with a width of $500 \mathrm{~m}$, the longitudinal trays deliver water up to $800 \mathrm{~m}$. During the irrigation season of these two fields, the water flows out to the discharge ditches through a closed bed drainage system.

Reclamation science and practice have developed two types of drainage - horizontal and vertical, a vertical drainage system has been used in the old irrigated part of Mirzachul, and horizontal drainage networks have been used in the newly developed part. Vertical drainage is used in separate lithologicalhydrogeological conditions, the profile of the soil should have a good permeable layer consisting of gravel, pebbles, sand, sand and their mixture, and a good hydraulic connection with the drainage layer of soil on this layer. In addition, horizontal drainage of various constructions was used in all other conditions. Ceramic, asbestos-cement, polyethylene and other types of pipes with a length of $0.3 \mathrm{~m}$ to $0.7 \mathrm{~m}$ were used for drainage. More than half a century after it was built today, these closed bed drainage systems are unable to perform their function due to the fact that the inside remains completely muddy due to untimely cleaning. As a result, the agricultural fields of Mirzachul oasis are rising, groundwater salinity and soil fertility 
are declining. In the system of trays for irrigation of farmland, the parts that are often damaged due to mismanagement are not able to perform their function, and water for irrigation is drained through ditches dug out of the ground, often leading to an increase in the intensity of soil subsidence, swamping, salinization, and suffocation processes. Today, it is important to study the reclamation of irrigated lands in agriculture, to study the area as an oasis geosystem, to map, to develop the necessary recommendations. The study of the reclamation status of the landscapes of Mirzachul oasis is based on the achievements of reclamation landscape in their assessment and mapping. Land reclamation is a doctrine of radical improvement of the composition of landscapes and increase their productivity, the important tasks of which are the development of principles and methods of landscape reclamation, development of the theoretical basis of landscape reclamation research, analysis of the interaction of reclamation devices with landscapes, landscape design, study of regional features of land reclamation, etc. $[6,8,10]$.

In the Gobi region of Mongolia, located in the arid region, small irrigation systems for fodder cultivation have been built since the 1970s. In China, too, arid climates have a large area, with 1.3 million deserts $\mathrm{km} 2$ or almost $14 \%$ of the country. The problem of adequate food supply for the rapidly growing population of the country is being solved by irrigated agriculture and development of previously vacant lands in the river valleys and parts of the desert, such as Sulexe, Joshuy (Edzin-Gol), Manas, Tarim, Konchadarya. Large mechanized farms have been established here, and along with arable crops, irrigated agriculture includes wheat, millet, corn, industrial crops - cotton and oilseeds. In some places in the foothills around the Taklamakon Desert, where groundwater flows to the surface, irrigated agriculture has been turned into oases. In the oases there is an opportunity to grow corn, rice, wheat, barley, cotton, various vegetables, fruits, grapes.

Due to the milder climate in the east and south of the Tibetan Plateau, which is the largest and highest mountain range in the world, it is possible to engage in animal husbandry (grazing goats, sheep and goats) as well as farming (barley, buckwheat, wheat, poppies, legumes). This region of Tibet is home to the world's highest agricultural barley, 4,500 meters above sea level. Only on the edges of the mountains, especially in the south, can you find oases where forest vegetation grows in deep river valleys. The main population engaged in agriculture is also concentrated in these oases.

The arid steppes and desert landscapes in the interior of the peninsula begin with landscapes of Lebanese cedars, pines and maquis bushes preserved on the washed-out limestone mountain slopes of the narrow Mediterranean coast of the Asia Minor Peninsula. Anthropogenic landscapes enter these landscapes through densely populated river valleys, and in oases formed on fertile alluvial soils, vines, olives, figs, almonds, mulberries are grown, cotton, corn, vegetables are grown. [3, $201 \mathrm{p}]$.

Although surrounded by seawater, the aridity of the deserts in the Arabian Peninsula and the Middle East, as well as the high growth rate of oil and gas production, have attracted the attention of countries in the region and industrial water supply requires attention to the issue of irrigation for irrigated agriculture. Today, while the region's most valuable natural resources are being mined from the deserts, agriculture continues to be a traditional area of economic activity for the peoples of the Arabian Peninsula and the Middle East. Agricultural production is concentrated in the countries of the Arabian Peninsula, in the Syrian desert, in the oases in the AlHajar desert: some of them are formed due to the emergence of groundwater as a spring. Such oases form the majority in the foothills of the Hijaz Mountains, along the foothills of the At-Tubayk Mountains in southern Arabia, and in the Naj region. The other part of the oasis was formed on the basis of artesian drill wells typical for the largest enumerated al-Hasa oasis (600 km2). There are also oases formed on the basis of the subterranean stream, among which irrigated crops are widely grown wheat, alfalfa, melons, vegetables and date palms. It is typical for coastal areas to specialize in vegetable and melon crops. Certain areas in the structure of cultivated lands belong to fruit trees and date palms.

At the bottom cliffs of the Arabian Peninsula are scarce springs, and palms are a reliable indicator that groundwater is usually located on the surface. Groundwater flows eastward along the slope of the strata and rises to the surface in the coastal plains near the Persian Gulf. The location and, to a certain extent, the size of the arable lands and settlements in the oases, including the capital of Saudi Arabia, Arriad, also depend on the wettest springs. In the abandoned small oases throughout the peninsula, farming is carried out in conjunction with nomadic pastoralism. This is typical of the deserts of Syria and Iraq, where the main crops are wheat, corn, vegetables, barley, alfalfa. The south of Iraq, Syria and the northern part of the Arabian Peninsula are mainly used as pastures.

Ancient farming is based on irrigation in the Negev Desert from water collected from surface streams of rain at the foot of plateaus and hills. Rainwater is collected in an area of 20-30 ha, which collects special water. This leads to the release of 3,000 to $6,000 \mathrm{~m} 3$ of water per year on 1 hectare of arable land. Many varieties of peaches, apples, pears, grapes, pistachios and cereals are grown in Shivt and Abd. Irrigation is widespread in the northern part of the Negev Desert. Rain and drip irrigation developed here, leading to the cultivation of high-yield crops in the winter. The problem of water supply in the south of the Negev was solved by the construction of a desalination plant, one 
of the largest of which is located in the Eilat district. The lower part of the Mesopotamian Plain, one of the oldest developed centers, is swampy in some places, with lakes and overflowing canals, as the surface water is difficult to drain. In High Mesopotamia, there are particularly large oil fields, and many oil rigs near them, along with agrolandscapes, reveal a unique landscape. The dry air and hot sunny days of this place, high temperatures, fertile alluvial soils well supplied with water are very suitable for growing cotton, rice, dates. Non-irrigated agriculture (barley, wheat) predominates on arable land, while rice and cotton are grown on arable land in the Mosul oasis and the Frot Valley. A large proportion of Arabs and Kurds are engaged in animal husbandry [2, $225 \mathrm{p}]$.

Despite the high demand for water in the mountainous region of Iran, no large hydraulic structures have been built on the country's rivers, and for centuries the population has been drawing water from ordinary dams and ditches, where rivers dry up, groundwater is used using a canal (a system of wells connected by tunnels several kilometers long). The largest oases are Isfahan, Kermanshah, Hamadan, Sheroz, Tehran and Mashhad oases in Iran, Mazar-e-Sharif, Kandahar and Jalal-Abad oases in Afghanistan. The serunum Peshawar Valley is located in West Pakistan. The oases in the mountainous region of Iran have been turned into flourishing orchards (where apricots, cherries, peaches, almonds, pomegranates, citrus fruits grow) and vineyards. Grain crops include rice, wheat, barley, corn, cotton, sugar beet and hemp. In the south, dates are of great importance in the lives of the population [2, $220 \mathrm{p}]$.

The deserts of Iran are mainly used as pastures. It is impossible to farm without irrigation. It led to the creation of a number of large and economically important oases here - Tehran, Qom, Mashhad, Kerman, Yazd and others. 2,500 years ago, groundwater in the foothills of Iran was supplied by the construction of underground canals. Underground canals (wings) water is discharged to the surface along the channels. Typically, the head of this device is located directly in the mountains in the zone of groundwater infiltration, and the part of the water that reaches the outlet to the consumer is much longer, sometimes tens of kilometers from its onset. The underground channel is connected to the surface of the land through wells, which are installed at a distance of $15-25 \mathrm{~m}$ from each other. They are used in the construction and operation of wings. The distance of the wings can be up to $50 \mathrm{~km}$ (Kerman district) and their flow rate can reach 20 to $200 \mathrm{~m} 3$ per hour. The region has 40,000 wings with a total length of 270,000 $\mathrm{km}$, which provide $35 \%$ of the country's water supply. The use of wings has led to the cultivation of cotton, fruits and oilseeds for export in Iran.

In his book "Under the Desert Sky" (1965), Ali Askar Mahajar, an Iranian traveler, vividly described the importance of corridors for Iran: "The wing itself embodies Iranian life. It rises from the depths with its water, and slowly reaches the outskirts of villages and towns, satisfying the thirst, supplying fresh blood to the barren fields. The wing is not like the humorous and violent mountain rivers. He will never show himself, for everyone will see that he will be weak and helpless in his service to the people in his own way. It flows silently and so hard that its power always serves as a source of life and hope." By now, most of the wings are depressed: some have been damaged, some have leaked water. Irrigation was carried out by drilling wells and using the surface flow of rivers flowing along the edge of the Iranian mountains [2, 287 p.].

In the northern part of the Iranian mountains, in the part of the Kambar lowland facing the southern shores of the Caspian Sea, and in the lower parts of the mountain slopes, many forests have been cut down. In the cleared lands, rice, legumes, corn, wheat, tobacco, and tea bushes are grown on the foothills; grapes, citrus fruits, figs, melons, etc. are planted in gardens and melons [3, 221 p.].

In the northwestern part of the Indian-Pakistan region, the climate was much more arid in the last Pleistocene, but about 10,300 years ago, due to an increase in atmospheric precipitation, the sernam phase of the climate began. However, the drought period began again 3,800 years ago and continues to this day with some change. The development of productive forces in the Tar Desert, India's most arid and sparsely populated area, is linked to irrigation. The Gang Canal, built in 1922-1927, turned barren deserts into fields of wheat, sugar cane, corn, and cotton. The transformation of the Tar Desert into an intensively irrigated agricultural region is associated with the construction of a huge Indo-Rajasthan canal, which began in 1958. The canal's 680-kilometer route runs through the driest part of the Tar Desert to Jaysalmar. The total length of the main and distribution canals is about $7,000 \mathrm{~km}$. The Rajasthan canal receives water from the Harike Dam, $3 \mathrm{~km}$ below the confluence of the Satlej and Bias rivers with the Punjab, and enters the Rajasthan area at $183 \mathrm{~km}$. Construction of the canal is scheduled for completion in 1987-1988, and when completed, it will provide 2.5 million cubic meters of water. hectares of land. The main irrigated crops here are wheat, cotton and a small amount of sugar cane. Barmir, Jaylsalmir, Umarkot and other oases were formed where the groundwater of the Tar desert flowed to the surface or was on the surface [2, 288 p.].

The oases are of great importance for the development of the Sahara Desert in Africa for agricultural purposes and as hotbeds of civilization. The oases are especially numerous in the desert region, formed by centuries of human labor. The most important crop in these oases is dates. The Sahara oases are located in areas where farming is not possible without constant irrigation. Their formation depends entirely on the provision of groundwater or at the expense of the Nile, Niger and other transit rivers. The development of a number of 
large oases is associated with the first of them. For the Algerian Sahara, the rapid population growth of Garday, Biskra, Uargli, Tuggurt, In-Salah and other oasis cities, as well as the "industrial oases", for example, the oil and gas industry is developed - Hassi Mesaud et al.

There are different types of oasis in the Sahara depending on the saturation of groundwater. Oases saturated with water from natural sources (Arabic "ayn") can often be found. Another type of source is a well (Arabic "hassi"), from which water is extracted using various drainage devices (Mzab oases). There are wells dug in the ancient valleys. Some of them are particularly common in the Tuggurt and Uargli districts. Tafilalet and Fetstsanda are characterized by small wells with a depth not exceeding $20 \mathrm{~m}$. The district of Biskra - the part of the Sahara that begins after the Atlas Mountains - the chain of all the oases of the Saur Ueda - these are called river oases, and the Ueda is partially filled with water at least once a year. Finally, the most remarkable and skillfully constructed structure for water supply to the oases is the foggara (wing, canals in Central Asia) - the groundwater catchment (groundwater pipes). Groundwater reserves in the Sahara Desert have been estimated at 15,300 km3. The largest reserves are concentrated in the Western Sahara [2, 290 p.].

The natural fertility of the brown soils, which have long been planted with ertut and olive instead of the maquis bushes of the Atlas Mountains, is very high, and a good harvest can be obtained if irrigated in the summer. Much of the coast, the foothills, have been cultivated and turned into an oasis where vines, citrus fruits, fruit trees, wheat, barley, and oats are grown.

Groundwater is the only source of water for irrigation in the New Valley, which includes five oases in Egypt, including Siva, Baharia, Farafra, Daxla and Harga. Since 1960, about 300 wells have been drilled here. After the construction of the Aswan Dam, the issue of discharging water from the reservoir through a $40 \mathrm{~km}$ canal was considered. Aquifers in the Sahara Desert have been studied in the Libyan desert and in the Algerian Sahara Desert. These layers supply water to many oases. There are also oases along the valleys, which receive water from streams beneath the valley. Almost all oases are the result of human activities, in which dates and cotton are grown. One of the largest oases in the world, the Nile Valley, grows the most cotton. Due to the construction of the Aswan Dam, the area of the oases was further expanded.

An extensive program to build water wells for irrigation has been implemented in the Sahara Desert of Algeria, As early as 1855, 450 wells were drilled in the largest oasis of the Sahara, Rir, in the Miocene and Pliocene sands. With the development of drilling techniques, the depth of wells and their total number increased. By the middle of the last century, their number here was 1,160. In the following years, the alb aquifer was developed in the Tidikelt oasis. Here the gross flow rate is $400 \mathrm{I} / \mathrm{s}$. seven wells were drilled to irrigate date palm plantations. In Mali, the operation "Wells" was carried out. In the mid-1970s, about 1,000 wells were recorded in the country. By the early 1980s, more than 400 new wells and boreholes were planned to be drilled in the herd and pasture areas to feed the country.

The Phoenician palm plays a key role in irrigated agriculture in the Sahara. It does not require soil and can be grown even between sands with low salinity groundwater. In South Algeria, Tunisia and Morocco alone, 10 million the surrounding palm trees are taken into account. Some of the Phoenicians were brought to the outskirts of the Sahara Desert. Usually in the oases, farmers plant three-tiered crops. The upper tier consists of date palms, in their shade - many species of fruit trees, and finally, in the above tier - annual cereals, vegetables, greens. The cultivation of cereals (wheat, barley), vegetables and fruit crops plays a secondary role. These products are consumed on the spot and cannot meet demand. The usual methods of irrigation here are - flooding or irrigation through furrows.

In the harsh conditions of the Libyan desert, the method of sprinkler irrigation is used. In 1967, during drilling for oil near the Kufra oasis, a huge freshwater reservoir was discovered at a depth of $1,400 \mathrm{~m}$. On the basis of this groundwater, cereals and vegetables were irrigated using a sprinkler system. One unit irrigates an area of 100 ha. By the early 1980s, irrigated desert lands had increased to 12,000 hectares in the Kufra and Serir oases. It should be noted that the method of sprinkler irrigation was able to withstand not only the climatic conditions in the desert (high evaporation rate, the presence of winds), but also the economically weak development of the area (lack of energy and manpower).

However, all groundwater is more or less mineralized, and a number of countries in North Africa - Libya, Algeria, Tunisia, Libya, there has long been a practice of using them to irrigate not only date palms, but also salt-tolerant crops such as olives, barley, alfalfa. In order to prevent the invasion of sands in the Sahara Desert, it is planned and implemented to create a "green belt" in North Africa. The Green Belt region, which includes Morocco, Algeria, Tunisia, Libya and Egypt, is part of a project prepared by the Arab League for Science and Culture (Alesco). It should not be imagined in the form of a forest zone planted perpendicular to the direction of the constantly blowing winds. This zone is forested with sands, and complex measures such as digging wells are carried out to make a protective belt.

The creation of such a zone in Tunisia began in 1975 , and by the end of this program, a green zone with a length of $1,120 \mathrm{~km}$ and a width of about $12 \mathrm{~km}$, stretching from the Moroccan border to Tunisia, was created. On the southern border of the Sahara, another 
"green belt" - the Sakhalin region - has been established. The project includes the countries of the region - Senegal, Gambia, Mauritania, Mali, Burkina Faso, Niger, Chad, Sudan and the Cape Verde Islands. Coffee plantations have been established on the windswept slopes of the Ethiopia mountain range at an altitude of $1800-2000 \mathrm{~m}$ above sea level, which is called the Kolla (hot zone). The voyna-dega region of the mountains, at an altitude of $2400-3000 \mathrm{~m}$, is home to the oldest agricultural culture, which has grown valuable varieties of wheat, rye and millet.

Water resources in the deserts of South Africa are very limited. Water supply is provided by drilling wells from rare natural sources to a depth of $300 \mathrm{~m}$ (2,100 wells were drilled in Kalahari in the 1970s) and temporarily constructing reservoirs on flowing rivers. Due to water scarcity, agriculture is also underdeveloped. Only in the dry valleys where the groundwater of the Molopo and Nosab rivers is relatively shallow can farming be done using surface streams. The water of the Orange River, which flows through the southern part of the Kalahari Desert, is used in part to irrigate the soils of the ancient delta of the Molopo River. Natural vegetation in 4/5 of the island of Madagascar has been cut down and burned and turned into rice, coffee, cocoa, vanilla and pepper plantations [2, 292 p.].

The natural resources of the North American deserts are quite diverse and rich. It is characterized by relatively favorable climatic conditions, richness of vegetation and complex geological structure of the region. One of the major challenges for deserts in the USA is water supply. The speed of population settlement and desertification is becoming possible due to the construction of large hydraulic structures. The construction of dams such as Glen-Canon, Hoover, Impirial, Davis, Parker will not only solve the energy problem in these areas, but also Colorado and led to the release of water from the Hila River to irrigate and supply arid areas in southern California. Irrigated agriculture covers an insignificant area of North American deserts - only $2 \%$. This is determined by the limited availability of irrigable land and the lack of water for irrigation. In irrigated lands, fodder crops (alfalfa) are often grown for livestock. In addition, sugar beet, cotton, vegetables will be planted and orchards will be multiplied. Groundwater is also used for irrigation. They are rich enough to sink.

The oases are not very common in the United States, the largest of which are Phoenix (Arizona) and Solton Si (California). Currently, there is a growing interest in the study of a number of plants known as "economic crops". These are primarily khohoba (yuyuba, Simmondsia chinensis) and guava (Parthenium argentatum). The seeds are extracted from the husk, which is composed of high-grade surkov oil, which can replace whale oil. It can be used as a fuel, a chemical additive to animal feed, and as a vegetable oil substitute oil. It covers 400 acres in Arizona and 1,500 acres in California. Guayula can replace rubber by giving latex. In the deserts of northwestern Mexico, the main area of agriculture is livestock (sheep and goats). Irrigated agriculture is secondary and underdeveloped. It is mainly based on the flow of the Colorado River the transit part of its confluence is formed in Rio Bravo del Norte. [2, 293 p.].

The agricultural influx into the Sechura Desert of South America is based on irrigation. The area of irrigated lands along the coast reaches 800,000 hectares. A 35 $\mathrm{km}$ long Sechura irrigation canal has been built in the urban-type Sechura village, which draws its water from the Pyura River. Cotton, rice, oats, legumes, citrus and others are grown. San Lorenzo's largest irrigation system is located between the Pyura and Chira rivers, irrigating 32,000 hectares of land. On the eastern edge of the Cordillera at the foot of the Cordillera in the Sechura Desert, a diamond irrigation system will be built, along with the San Lorenzo system, to provide a solid foundation for the country's economic development in the north.

The development of the Atacama Desert has been going on since ancient times. Coastal fishing and farming were the main occupations of the locals. When Pedro de Valdivia crossed the Atacama Desert in 1540 , he identified 1,000 acres of arable land in the Kalama region. Agriculture in Atakama is underdeveloped. It is marked by ancient agricultural centers - oases along the banks of several rivers. The Kalama oasis is of great importance, as oats, alfalfa, cotton and sugar cane are grown on the irrigated lands of the oasis. Irrigation has led to a significant increase in the cultivation of tropical and subtropical crops such as olives, figs, citrus, peaches. Here cattle-breeding is extensively developed everywhere, and mainly llamas are bred. "Lama" is a South American camel, which is used as a transport animal, and its meat is consumed, and wool is used to make clothes, ropes, sacks, oil candles, leather - shoes and other everyday items. The dry manure of the lamas serves as a good fuel. An adult llama can carry a load of up to $100 \mathrm{~kg}$ and travel 30-35 km per day with a load of up to $60 \mathrm{~kg}$ and can withstand drought for several days [2, 294 p.].

\section{Conclusion}

The scarcity of surface water in Australia determines the absence of large agricultural oases here. The only major center of plant cultivation is Alice-Springs, where citrus fruits and vegetables are grown on a small area. The great potential for the development of the periphery of the deserts depends on its groundwater, which makes the continent much richer. According to Australian experts, the use of groundwater to irrigate pastures and provide people with water is cheaper than building a reservoir to regulate the temporary flow of rivers. The lack of surface currents in the Australian desert requires water to be transported from the northwestern regions of the country and the transportation of icebergs from the Antarctic waters as 
an option. There is also a scheme to divert water from the Tally, Herbert and Berdekin rivers to the southeast of Australia via the Flinders and Thomson (a tributary of the Coopers Creek that flows into Lake Eyre). The country also has a project to create a large artificial lake with an area of 9.6 thousand km2 in the Air basin, where it is planned to bring ocean water through a system of canals. Distilled seawater is used for irrigation and water supply [2, 295 p.].

\section{References}

1. Abdulqosimov A.A., Abdurahmonova Yu.X., Davronov K.K. Landscapes and geoecology of the Zarafshan basin oasis. "Economics and Finance",Tashkent:. 2017. P. 4.

2. Babaev A.G., Drozdov N.N., Zonn I.S., Freykin Z.G. Pustyni. "Mysl". Moscow:.1986.

3. Ryabchikov et al. Natural geography of the continents of the world. Tashkent:. 1966.

4. Toshboyev Z.M., Yarashev K.S. Formulation and Development of Mirzachul Landscapes. Nature and Science. Volume 18, Number 2. February 25, 2020. Marsland Press. Multidisciplinary Academic Journal Publisher

5. Toshboev Z.M. Ameliorative-technogenic elements in the structure of oasis landscapes Mirzachul. Nauch.konf. Ufa, Bashkortostan. Russia:. 2020. P.143-145.

6. Toshboev Z.M., Kholmirzaev J.E. The role of irrigation in the formation of Mirzachul oasis landscapes. // Science and education in the modern world. Challenge XXI century. Mejdunar. scientific practice magazine. Nur-Sultan, Kazakhstan:. 2020.

7. Toshboyev Z.M. Relief forms of Mirzachul oasis. ACADEMICIA An International Multidisciplinary Research Journal. Nol. 10 Issue 11, November 2020 (Double Blind Refereed \& Peer Reviewed Journal) Impact Factor: SJIF $2020=7.13$. P. 5.

8. Toshboev Z.M. Formation and development of Mirzachul oasis landscapes. GEOGRAPHY: NATURE AND SOCIETY - SJIFactor.

9. Toshboev Z.M., Zikirov B.Ya., Qayumova Sh. The role of rivers in the composition of anthropogenic landscapes. // Proceedings of the scientificpractical seminar of the Association of Geographers of the Fergana Valley. Tashkent:, 2016.

10. Toshboyev Z.M., Kushmatov B.B., Murodullayev H.H. Anthropogenic landscape types in mirzachol. International Conference on Digital Society, Innovations \& Integrations of Life in New Century P. 1-3.

11. Toshboev Z.M., Rakhmatov G., Haqberdiev O. The role of rivers in the formation of oasis landscapes. XII Global Science and Innovation 2021: Central Asia. Series "Geographical sciences" Nur-Sultan, Kazakhstan:, February, 2021 P. 16-19. 